\title{
Sobre la enseñanza de la Filosofía
}

\author{
«Los dioses no hacen filosofía» \\ (Platón, El Banquete, 201e) \\ «La filosofia no es una disciplina escolar. \\ Es el hombre mismo" \\ (Heidegger, Was ist Metaphysik? p. 41)
}

Son muchas las cosas que se han dicho sobre la enseñanza de la filosofía, pero uno tiene siempre la impresión de que no se insiste suficientemente en lo principal: la vida, la experiencia apasionada de lo real como punto de partida de la reflexión y de la enseñanza. El análisis del carácter extraño e íntimo de la filosofía revela que lo principal en su enseñanza radica en el maestro que la imparte. El olvido o descuido de esta característica peculiar puede reducir la enseñanza de la filosofía a un paseo por una «galería de opiniones» en lugar de posibilitar la introducción en el ámbito filosófico. La «historia íntima» sobre la que se construye necesariamente la filosofía debe orientar las clases hacia la lectura de obras, y no de textos, y a corfirmarnos en la vieja idea de que solamente los dioses no hacen filosofía. El hombre como tal no puede evitarla. Esto nos decubre el sentido de la filosofía y del hombre como trascendencia del entorno. Que existan o no los dioses y los cielos, la filosofía es, como dijo Platón, Iris, hija de Maravilla, el arco y el puente polícromo lanzado sobre el firmamento que une la tierra de los hombres y los cielos de los dioses '. Es decir, la filosofía libera al hombre de la asfixia de lo empírico y con ello le ofrece la posibilidad de garantizar un mundo humano.

La actual inflación literaria sobre métodos pedagógicos, el desafío y el reto que el pensamiento de nuestros días, orgulloso de asistir al «cortejo fúnebre de la familia, de la palabra y el ser», lanza contra la filosofía revelan el olvido de su origen y dan buena cuenta de la penuria en la que se halla hoy la filosofía. Si la filosofía no puede ignorar la situación y el medio en el que se desarrolla, el profesor de filosofía no puede descuidar el origen inevitable-

1. Platón, Teeteto, 155a. 
mente humano de la misma, de donde recibe la fascinación y la fuerza necesaria para ser transmitida.

Nos proponemos abordar aquí este tema con arreglo a los apartados que siguen:

1. El coraje de enseñar hoy filosofía.

2. El carácter extraño de la filosofía.

3. El testimonio de la verdad.

4. El reproche de abstracta.

5. La enseñanza del saber filosófico no es ya la entrada en filosofía.

6. Lo inactual de la filosofía.

7. Comunicar lo incomunicable.

8. ¿Lectura de textos o lectura de libros?

9. Consideración final.

\section{El coraje de enseñar hoy filosofía}

El profesor de filosofía, que se piense las cosas en serio, no podrá menos de estremecerse atemorizado ante lo que significa enseñar hoy filosofía, sobre todo si ha de impartirla a los que se inician en ella. Decía Hegel, refiriéndose a su época, que Metafísica es la palabra ante la cual... todos se apresuran a escapar como si se tratara de un apestado. Nuestra situación no es mejor que la de entonces. Michel Foucault, en «Las palabras y las cosas», el manual que reemplaza el existencialismo, nos anuncia claramente que el hombre del «logos» está terminado y va a desaparecer. «En nuestros días, dice expresamente, el hecho de que la filosofía esté siempre y todavía en vías de terminar y el hecho de que ella, pero más aún fuera de ella y contra ella, tanto en la literatura como en la reflexión formal, se plantee la cuestión del lenguaje, prueba, sin duda, que el hombre está en vías de desaparecer» ${ }^{2}$. En la página siguiente nos dice que «el hombre es una invención cuya fecha reciente muestra con toda facilidad la arqueología de nuestro pensamiento. Y quizá también su próximo fin" ${ }^{3}$. En la misma obra afirma también que la metafísica del infinito se ha hecho inútil desde el momento en el que los contenidos empíricos se separan de la representación e implicaron en sí mismos el principio de su existencia ${ }^{4}$.

Las expresiones de François Châtelet suenan más rotundas. «No se trata, dice, de salvar a la filosofía. Está muerta y no hay por qué devolverle la vida a figuras de museo" ${ }^{5}$. ¿Qué profesor de filosofía no se angustia al tener que impartir sus clases en una época que se caracteriza por la muerte del pensamiento especulativo? En la «Historia de la locura en la época clásica», Michel Foucault insiste una vez más en hacer tabla rasa de un saber que ha estado ob-

2. Foucault, M., Las palabras y las cosas. Ed. siglo XXI, Madrid 1978, p. 374.

3. Id., p. 375.

4. Id., p. 308.

5. ChÂtElEt, F., La filosofía de los profesores. Ed. Fundamentos, Madrid 1971, p. 18. 
sesionado por los fundamentos. Los 'fundamentos' son contrarios a la naturaleza misma de la filosofía, pues al fijarla necesariamente en un tiempo, su búsqueda se detiene, desaparece la interrogación,todo se afirma o se niega, y la razón se convierte en 'desrazón'. La locura, las cárceles, los asilos son los conflictos y las contradicciones en las que se ve envuelta una sociedad que se ha erigido sobre la 'razón fundamental', sobre un principio-fundamento. La historia de la locura revela la enfermedad de muerte que aqueja la sociedad que la produce. Se precisa, por tanto, acabar con la razón fundante, con la razón de los principios y con el saber sobre el hombre fundado en dicha razón. Hay que acabar con ese pensamiento que pretende 'orientar' al hombre, darle un equilibrio ontológico e instalarle en una morada estable sobre la tierra. Si en alguna parte hay que instalarle, esto ha de ser «en esa región en la que ronda la muerte, en la que el pensamiento se extingue, en la que la promesa del origen retrocede indefinidamente» ${ }^{6}$. El hombre deja así de ser pensable. "La muerte de Dios y el último hombre han partido unidos" ${ }^{7}$.

La razón que en Platón, Aristóteles, Descartes o Hegel se caracterizaba por su afán de regirlo todo, que se adjudicaba el saber de los saberes, se ve ahora reducida al silencio y a la escucha. La razón se ha quedado sin raíces. Es Descartes quien nos ha dejado la mejor imagen del carácter arborescente de la filosofía, la filosofía como àrbol-raíz. «Así, nos dice, toda la filosofía es como un árbol, del cual las raíces son la metafísica, el tronco es la física, y las ramas que brotan son todas las demás ciencias» ${ }^{8}$. Filosofar es plantar.

La obrita 'Rizoma' de Gilles Deleuze-Felix Guattari es, por el contrario, un manifiesto contra el fundamento arborescente. Su imperativo dice: «Ne plantez pas, piquez». No plantéis jamás, picad ${ }^{9}$. El árbol-raíz, símbolo de la voluntad de fundamento que busca una bella totalidad orgánica, debe ser sustituido ahora por el rizoma. «Un rizoma, nos aclara, como tronco subterráneo, se distingue absolutamente de las raíces y raicillas. Los bulbos, los tubérculos son rizomas» ${ }^{10}$. «Un rizoma, nos dice más adelante, no responde a ningún modelo estructural o generativo. Es tan ajeno a toda idea eje genético, como a la de estructura profunda" ${ }^{11}$. El mundo no es un 'cosmos-raiz', sino un 'cosmos-raicilla' ${ }^{12}$, que la razón debe renunciar a su impulso de interiorizar.

También el psicoanálisís, el existencialismo, el marxismo y positivismo deben sin duda, su irresistible fascinación a la lucha despiadada contra la tra-

6. FoucAuLT, M., o.c., 372.

7. Id., p. 373.

8. Citado por M. Heidegger en su 'Einleitung' a 'Was ist Metaphysik?. Ed. Vittorio Klostermann. Frankfurt A.M., 1960, p. 7.

9. Deleuze, G.-Guattari, F., Rizoma. Pre-textos, Valencia 1977, p. 60.

10. Id., p. 15.

11. Id., p. 30 .

12. Id., p. 15. 
dición establecida. Sin embargo, todos ellos son tan perniciosos como el saber antiguo, pues no han renunciado a los fundamentos, sino que han instalado otros nuevos.

G. Deleuze y F. Gauttari son conocidos, sobre todo, por su obra 'El antiedipo', en la que el psicoanálisis recibe una dura crítica. El deseo sale del angosto campo del inconsciente, erigido en ciencia, para convertirse en un flujo universal que se encuentra en todas partes convirtiendo al hombre en una 'máquina deseante'. Hay máquinas en cualquier lugar. «El seno es una máquina que produce leche, y la boca, una máquina acoplada a aquélla» ${ }^{13}$. Al lado de esta máquina-voluntad, Edipo es todavía una «fantástica represión de las máquinas deseantes» ${ }^{14}$. «El psicoanálisis, nos dice más claramente, en vez de participar en una empresa de liberación efectiva, se une a la obra de represión burguesa más general, la que consiste en mantener a la humanidad europea bajo el yugo del papá-mamá, lo que impide acabar con aquel problema» ${ }^{15}$.

No se trata ya de reemplazar, de sustituir. Esto es algo prohibido a la razón. Se trata simplemente de criticar y destruir. El escepticismo, la anarquía y la irreverencia vienen a constituirse en los atributos fundamentales de la razón. 'Pensar' al estilo griego es una depravación del hombre. Nunca se ha humillado tanto a la razón sistemática.

Heidegger había rechazado también el pensar que fundamenta. La concepción de Dios como fundamento último ha sido, según él, la causa del nihilismo actual, del ateísmo y de la impiedad. De hecho, Heidegger concibe el ser como «Ab-Grund», sin-fundamento, como abismo. Pero en el filósofo de Messkirch el ser era todavía el 'primum cognitum', la posibilidad del conocer y del pensar, la bendición y la gracia del pensamiento. Al hombre no le cabía pensar arbitrariamente. Su pensar, el más personal era el pensar del ser.

Con esta nueva filosofía no solamente se despoja a la razón de su función 'fundante'; sino que la deja desamparada del ser. El ser ni existe ni es. Este rechazo de la capacidad trascendente de la filosofía, este 'analfabetismo trascendente' como diría Gusdorf, refleja la gravedad del actual nihilismo filosófico. Hoy no se trata de renovar nada ni actualizar nada, se trata de oponerse a todo, sin más. Se reconoce, pues, la imposibilidad de pensar y el fracaso de la razón.

Louis Althusser se ha encargado también de despojar al marxismo de su carácter humanista, de romper sus lazos con la antropología, de eliminar al hombre como punto de referencia esencial del pensamiento. El marxismo, se nos dice, es antihumanista, no tiene al hombre como centro. Tener al hombre como centro supondría disponer de una representación ideal y abstracta del

13. Deleuze, G.-Guattari, F., El antiedipo. Capitalismo y esquizofrenia. Ed. Barral, 1974 , p. 11.

14. Id., p. 12.

15. Id., p. 54. 
hombre que habría que llevar a término. Ahora bien, las ideologías son interpretaciones ideales del mundo, no interpretaciones reales. Las ideologías caracen de práctica y de objeto, su reino son las ideas y las palabras. Pueden ser brillantes como sistemas, pero vacíos de realidad. Por esta razón el filósofo no se equivoca nunca ${ }^{16}$.

El pensamiento de Jacques Lacan y Levi-Strauss no se ha portado mejor con el hombre. El sujeto ha dejado de ser el lugar de la palabra, de la razón y del sentido. Lo que caracteriza la teoría del sujeto es precisamente la ausencia del hombre, al sujeto se le ha deshumanizado. El 'yo hablo' se convierte en 'ello habla en mí'. El hombre no piensa.

La filosofía analítica, la otra gran corriente actual del pensamiento, permanece fiel a Ludwig Wittgenstein cuando decía: «El verdadero método de la filosofía sería propiamente éste: No decir nada, sino aquello que se puede decir; es decir, las proposiciones de la ciencia natural - algo, pues, que no tiene nada que ver con la filosofía-; y siempre que alguien quisiera decir algo de carácter metafísico, demostrarle que no ha dado significado a ciertos signos en sus proposiciones. Este método dejaría descontentos a los más - pues no tendrían el sentimiento de que estábamos enseñándoles filosofía-, pero sería el único estrictamente correcto» ${ }^{17}$.

'a muerte del pensamiento especulativo se da ya por hecho. La culpa, no obst nte, de que la ceremonia funeraria no se haya celebrado aún y que la filosifía no haya sido arrojada al desecho de la historia la tienen los profesores de filosofía que 'vagabundean entre tumbas'. Pero ellos mismos son conscientes de su desaparición como lo testimonia la importancia que cada día va adquiriendo entre ellos la historia. La historia ha venido a ocupar el vacío dejado por la filosofía. Pero ni siquiera esto ha conseguido ocultarlo porque se va a la historia sin filosofía, lo cual convierte a aquella en una galería de opiniones que es, como dice Hegel, un saber de cosas inútiles. También se ha recurrido a los textos fragmentados y a los comentarios de textos, pero no se ha conseguido eliminar la impresión de que con ello se quiere reemplazar la filosofía viva. La historia en sus textos sólo aparece cuando no existe una gran filosofía original.

La situación no puede ser más desoladora. Hay que contar también que la sensibilidad de los alumnos que frecuentan las clases se ha desarrollado en la atmósfera que han captado los filósofos del momento. El alumno está socialmente incapacitado para pensar. El profesor necesita armarse de coraje, valor y paciencia.

Aunque no podemos cerrar los ojos a esta evidencia, conviene constatar que la realidad es también otra. Por más que se anuncie y proclame no está

16. Althusser, L., Curso de filosofia para cientificos. Ed. Laia, Barcelona 1975, p. 17.

17. Wittgenstein, L., Tractatus Logico-Philosophicus. Ed. Alianza Universidad, Madrid 1975, prop. 6.53, p. 203. 
perdido todo. La esperanza procede de la naturaleza misma de la filosofía. No se puede negar la filosofía sin hacer filosofía. Se le puede negar su pretensión de hipotecar el pensamiento, de instalarse en el tribunal de la verdad y juzgarlo todo. Se le puede negar su importancia social y su inserción en el conjunto de los conocimientos estimados esenciales. En el fondo, esto no es negar la filosofía, sino la filosofía tal como ha sido hasta el momento. Cada pensador trata de decir y justificar a su modo por qué la filosofía no puede continuar siendo lo que es, pero lo hace desde una filosofía, desde una filosofía que es, en nuestro caso, crítica de toda filosofía sistemática, de todo principio organizador y de todo dogmatismo. Por otro lado, tampoco este principio puede llevarlo muy lejos si no quiere incurrir en el dogmatismo de la crítica. El pensamiento actual busca, sin haberlo encontrado aún y sin sospechar cuál pueda ser, un nuevo estilo de filosofar.

Conviene igualmente recurrir en estos momentos al sentido histórico, tener en cuenta las vicisitudes por las que pasan los grandes sistemas filosóficos. Toda filosofía, dice Hegel, es irrecusablemente «la conciencia de su tiempo». Por mucho que el individuo quiera estirarse, jamás podrá salirse verdaderamente de su tiempo, como no puede salirse de su piel ${ }^{18}$. La filosofía expresa las necesidades y las preocupaciones de una época. Esto manifiesta, a su vez, la contradicción interna de toda filosofía que presentándose como suprema y necesaria, es contingente y limitada. Descartes triunfa sobre la escolástica, Kant sobre Descartes, Hegel sobre Kant, etc. Toda filosofía se verá necesariamente suplantada por aquella que mejor recoja, funde y legitime las urgencias del momento. Pero, en realidad, la sucesión de la hegemonía no tiene tanto interés bajo el aspecto docente. Lo más importante para la enseñanza de la filosofía no es fijarse en los elementos negativos por los que se pierde la supremacía, sino en descubrir la necesidad que la obligó a surgir y cómo reabsorbe los principios esenciales alcanzados en el pensamiento precedente. Aristóteles, al rechazar el platonismo, no negó las ideas, simplemente dejaron de ser el principio absoluto de su sistema. Los elementos cambian de lugar. «El patrimonio recibido de las generaciones anteriores, nos dice Hegel, queda reducido al nivel de una materia prima que el espíritu se encarga de metamorfosear. Lo recibido se transforma de este modo y la materia, al elaborarse, se enriquece a la par que se transforma ${ }^{19}$. Con ello la historia de la filosofía se vertebra, deja de ser un vagabundear entre tumbas para convertirse en algo vivo y constantemente actual. El pasado no es más que uno de los aspectos de las cosas. "La novísima filosofía, afirma Hegel, no es sino el resultado de todos los principios precedentes; en este sentido puede decirse que ninguna filosofía ha sido refutada. Lo refutado no es el principio de esta filosofía, sino

18. Hegel, G.W.F., Lecciones sobre la historia de la filosofía. Ed. F.C.E., México 1977, p. 48.

19. Id., p. 10. 
solamente la pretensión de que estẹ principio sea la determinación última y absoluta» ${ }^{20}$.

La filosofía, concebida por dentro en su entramado, puede cobrar un sentido y despertar el interés del alumno. No supone todo esto que el profesor de filosofía sea un filósofo, pero sí se le exige, dado el carácter peculiar de la filosofía, que a la hora de reelaborar la doctrina y buscar las formas de readaptación al alumno no permanezca pasivo y exterior a lo que trata, sino que al repensarlo personalmente reobre en todo ello su convicción y pueda interesar. La filosofía no es la enseñanza de lo muerto y enterrado, sino de lo presente vivo. Negar la filosofía sólo se puede hacer invocando la filosofía. La filosofía tiene un carácter extraño.

\section{El carácter extraño de la filosofía}

Decía Hegel que la filosofía es «el mundo al revés». Este afán implacable que tiene la filosofía de poner las cosas 'patas arriba' la convierte, a la hora de hablar sobre ella o transmitirla, no solamente en algo incomunicable, sino, sobre todo, en algo constantemente cuestionable. ¿Cómo podríamos hablar de la enseñanza de la filosofía si, apelando a la filosofía, ignoramos lo que es filosofía? Platón nos advertía ya que la filosofía tiene una paternidad desconcertante. Aunque no es una diosa porque los dioses no hacen filosofía, su extraña naturaleza le viene de ser casi una diosa. Es hija de Penia, de la sabiduría, y también de Poros, la penuria. En ella la suma riqueza se junta con la suma indigencia. Por ello, el hombre pasa toda su vida filosofando ${ }^{21}$. El hombre no puede dejar de filosofar. Los filósofos presentan, cada cual, sus filosofías como algo hasta entonces inédito. Emprenden la gran aventura del espíritu en solitario, convencidos de que todo está aún por hacer. A todos les invade un anhelo de comenzar desde el principio, evitando los 'errores' del pasado. Los jonios oponen el 'Logos' al 'Mythos. Pero con ello no se acabó con la mitología. Si la mitología fue la primera filosofía, la filosofía pasó a ser la segunda mitología, algo que siempre hay que desmitificar y cuya tarea está siempre por hacer ${ }^{22}$. Y todos los que no han querido aceptarla así, los que han querido reducir a ciencia la filosofía, han terminado por fracasar en su empeño destruyéndola o aceptándola como algo irracional imprescindible. Así Wittgenstein pensaba que sólo se pueden plantear preguntas que tienen sentido, y tienen sentido aquellas preguntas que tienen respuesta, y tienen respuesta aquellas preguntas cuyas respuestas son científicamente, experimentalmen-

20. Id., pp. 40,44,41.

21. Platón, El Banquete, 201e, $202 \mathrm{e}$. 287.

22. Gusdorf, G., Mito y metafisica. Ed. Nova, Buenos Aires, 1960, pp. 267, 268, 283 y 
te verificables. De aquí se deducía que admitir el nexo causal es una superstición ${ }^{23}$, que la muerte no existe porque no es vivida ${ }^{24}$, y que la solución del problema de la vida está en la desaparición de este problema ${ }^{25}$. Sólo se puede hablar de las proposiciones científicas, es decir, de algo que no concierne en absoluto a la filosofía ${ }^{26}$. En suma, sobre lo que no se puede hablar, hay que callar ${ }^{27}$. Pero a Wittgenstein le ocurre lo que aconteció a Kant que no consiguió imponer el silencio a la filosofía porque la ciencia o las respuestas científicas ni son toda la vida, ni conciernen, en definitiva, a la vida. Wittgenstein se expresa con toda claridad: «Sentimos que, aun cuando todas las posibles preguntas de la ciencia recibieran una respuesta, los problemas de nuestra vida permanecerían totalmente intactos» ${ }^{28}$. Kant había afirmado también que todos los metafísicos quedaban suspendidos solemnemente de sus funciones. Pero tras largo y penoso camino sostenía que es un saber del que no se puede prescindir en absoluto, que no podemos llegar nunca a interrumpir completamente su respiración porque «no hay medio alguno de satisfacer esta apremiante necesidad que es, aún, algo más que un mero deseo de saber» ${ }^{29}$.

Wittgenstein percibió claramente que la filosofía no tiene una función científica, sino una función superior a la ciencia. La ciencia puede facilitar, y facilita de hecho, las cosas de la vida, pero permanece extraña a ésta. Sólo la filosofía es entrañable a la vida. Por eso, decir que la filosofía está más allá de lo decible, de lo científicamente decible, no es un reproche, sino el elogio que la coloca al lado de la vida. Pensar en el sentido de la vida no es un pensamiento 'científico', pero sí filosófico. Es consolador reconocer que la huida al silencio es la huida a la filosofía y a la vida.

La pasión del filósofo por comenzar 'desde el principio' no responde a un deseo de destrucción del pasado, sino a la necesidad de dar un nuevo testimonio de lo real. Cada pensador es un nuevo testigo de la realidad genuina, auténtica, de la realidad limpia de prejuicios y presuposiciones. Filosofías tan diversas como la fenomenología y la filosofía analítica se presentan como 'filosofías sin presupuestos'. Poco importa en este lugar si el hombre no puede salirse de su tiempo como no puede salirse de su piel, lo importante en nuestro caso es comprender que el filósofo comienza tras haber quedado fascinado, comprometido e interpelado, estremecido de parte a parte en todo su psiquismo, por lo real y que la fidelidad a las cosas es su primer deber. La vida precede al sisterna. El 'Discurso del método' es un diario antes que un sistema. Lo

23. WitTGenStein, L., o.c., prop. 5.1361, p. 119.

24. Id., prop. 6.4311, p. 119 .

25. WiTtGenstein, L., o.c., prop. 5.1361, p. 119.

26. Id., prop. 6.53, p. 203.

27. Id., prop. 7, p. 203.

28. Id., prop. 6.52, p. 201.

29. Kant, Prolegómenos a toda metafísica del porvenir. Ed. Porrúa, México 1973, p. 101. 
fascinante es precisamente la pasión de búsqueda intelectual. La historia de la filosofía como historia de los pensadores será siempre anónima e impersonal si no va acompañada de su historia íntima. Sartre nos dice que la frase «la existencia precede a la esencia» tiene que ser vivida para ser sincera ${ }^{30}$. La filosofía comienza siendo un 'diario íntimo' o un 'diario de metafísica' y debe serlo hasta el final si quiere ser para el hombre más útil que la ciencia. La ciencia tiene respuestas, pero no las que necesitamos; hace preguntas pero no las que nos atormentan. En filosofía, detrás del entramado conceptual hay toda una historia apasionada. Este carácter personal de la filosofía no solamente coloca al profesor por encima de los programas, sino que a la hora de enseñar es más importante su reconocimiento que el aprendizaje riguroso del sistema.

\section{El testimonio de la verdad}

Lo principal, pues, en la enseñanza de la filosofía no consiste en grandes e inteligentes programaciones ni en ambiciosos proyectos. Lo fundamental radica en el maestro que la imparte. Es una antigua experiencia que el filósofo M. Heidegger nos recuerda evocando la figura de Abraham de Santa Clara. Nos dice textualmente que «lo decisivo y determinante en la docencia no es la estructuración fría de los planes y proyectos de enseñanza, sino el ejemplo y el ideal vivo del maestro" ${ }^{31}$. Lo esencial es el testimonio. La filosofía, en efecto, parte de la realidad profundamente vivida. A esta vivencia es a la que se refieren los antiguos cuando dicen que la filosofía tiene su comienzo en la admiración ${ }^{32}$, admiración no tanto de que existen las cosas cuanto de que uno mismo existe. De hecho, el hombre cuando pregunta es, en definitiva, por sí mismo por quien pregunta. Heidegger nos dice que no puede ponerse ninguna cuestión metafísica que no incluya en sí misma al que interroga, es decir, que el que interroga sea, en el fondo, el interrogado ${ }^{33}$. El destinatario de la filosofía es uno mismo. Tenía, pues, razón Kant cuando afirmaba que la filosofía no es un arte para formar hombres, sino para formarse a sí mismo. Poco importa la doctrina o el sistema filosófico que enseñe el profesor, lo que importa es que el alumno 'vea' que detrás de aquel sistema hay todo un drama humano y que el profesor testimonia ese tormento íntimo. Sin esa carga profunda psíquica la filosofía es mero formulismo, una abstracción perfectamente inútil. El alumno que se inicia en la filosofía capta esto sólo en la persona del profesor. Por ello, lo que el maestro debe traslucir en sus enseñanzas no son las

30. SARTre, J.-P., L'existentialisme est un humanisme. Ed. Nagel, Paris 1960, p. 101.

31. Heidegger, M., Úber Abraham a Santa Clara, en «Martin Heidegger zum 80 Geburtstag von seiner Heimatstadt Messkirch». Vittorio Klostermann. Frankfurt am Main 1969, p. 47.

32. ARISTÓTEles, Metafísica, 1,c.2.

33. Heidegger, M., Was ist Metaphysik? Ed. Vittorio Klostermann. Frankfurt am Main 1969 , p. 24. 
articulaciones de las partes en las que artificialmente, y sólo desde un punto de vista pedagógico justificables, se divide la filosofía, sino la articulación de la historia íntima personal. No se puede olvidar que dar una lección de filosofía es dar una lección de vida. Todo lo demás no tiene importancia. Los métodos, incluso, pueden ser accidentales. El método lo da la riqueza y profundidad vivencial del maestro.

\section{El reproche de abstracta}

El gran inconveniente de la filosofía y que le causa no pocos reproches, lo constituye, efectivamente, su propia naturaleza que siendo singular y concreta no puede presentarse a no ser de un modo abstracto y universal. Cuanto más profundamente concreta, personal e individual se presenta en la vida de cada uno, tanto más universal aparece. Nuestro ser personal es al mismo tiempo universal. En realidad, toda experiencia personal se formula en teoría universal. El filósofo despliega su filosofía en panorama desde un punto de vista. Esta es la paradoja en la que se desenvuelve la filosofía y que le ha valido los reproches de 'abstracta', es decir, indiferente y ajena a la realidad del individuo. Sin embargo, la filosofía se nutre de los objetos más concretos y vitales. Platón elabora una filosofía para reconciliarse con la muerte ${ }^{34}$ y cuando Aristóteles se pregunta de una manera abstracta qué es el ser como una tarea que desde un principio había emprendido el pensamiento sin haber llegado a una solución satisfactoria ${ }^{35}$, estaba, en el fondo, formulando la pregunta concretísima y personalísima que un día se hizo también san Agustín y se formuló Heidegger: «¿Qué hay más cerca de mí que yo mismo?». Evidentemente, nada. $\mathrm{Y}$, sin embargo, tiene que responder: «Me he hecho a mí mismo tierra de dificultad y de excesivo sudor» ${ }^{36}$.

La pregunta por el ser no tiene sentido si en sí no equivale a la pregunta por el sentido del hombre o de la vida. Aristóteles, interrogando el ser, exige a la filosofía lo mismo que A. Camus esperaba de ella cuando decía: «juzgar que la vida vale o no vale la pena de que se la viva es responder a la pregunta fundamental de la filosofía». Los caminos emprendidos y los métodos pueden ser diversos. Puede pensarse que para solucionar el problema hay que hacerlo a partir de los seres exteriores o que el camino debe pasar por el desfiladero de la interioridad. En uno y otro caso es el hombre el que interroga y el interrogado. La filosofía es humana. No es nunca la razón pura, limpia, aséptica la que piensa, sino el hombre entero. Bastaría resurir a los numerosos testimonios que atestiguan claramente que la especulación intelectual más abstracta está siempre en estrecha dependencia de una vida concreta, personalísima, vital.

34. Platón, Fedón 81a.

35. ARISTÓteles, Metafisica, VII, c.1.

36. Heidegger, M., Sein und Zeit. Ed. Max Niemeyer, Tubingen 1957, p. 43-44. 
Traigamos como ejemplo la confesión que nos hace Baruch de Spinoza de la necesidad personal que le impulsó a filosofar. He aquí el texto biográfico tomado de su «Tractatus de intellectus emendatione. Et de via, qua optime in veram rerum cognitionem dirigitur»:

«Después de enseñarme la experiencia que todas las cosas que frecuentemente acontecen en la vida diaria son vanas y fútiles. Después de darme cuenta que todas las cosas que temía no eran ni buenas ni malas a no ser en cuanto que me afectaban, determiné, entonces, investigar si existía algo que fuera el bien verdadero y comunicable, y que sólo él, abandonadas todas las demás cosas, fuera capaz de conmover mi espíritu. Más aún, decidí investigar si existía algo que, una vez encontrado y conseguido, me proporcionara alegría suma y continua por toda la eternidad".

La filosofía comienza cuando se revela toda la penuria ontológica del hombre y de su entorno inmediato, cuando se siente naufragar sin tener nada a aqué agarrarse, cuando se pierden los puntos de referencia, cuando todo se hace oscuro y uno se maravilla de que pueda existir algo. Esta oscuridad no es absoluta, es como una "noche luminosa» en la cual los seres se presentan como un milagro enigmático. El milagro de los milagros no hay que buscarlo en ningún fenómeno extraordinario y poderoso, sino sencillamente en descubrir que las cosas existen. Resolver este milagro enigmático ha sido, es y será la obsesión del hombre.

La filosofía comienza por nosotros mismos y termina en nosotros. Nosotros somos el principio y el término. La filosofía es la vida de cada cual cuando cada cual vive su vida; y cada cual la vive cuando se cuestiona de raíz. Para el hombre, dice Marx, la raíz es el mismo hombre. Por esto mismo, lo que la filosofía busca es más real que todos los artefactos últimos que la ciencia más reciente haya podido descubrir. En filosofía no hay objetos que sean manipulables, controlables, verificables y, sin embargo, lo que urge a la filosofía es más necesario que todo lo que el hombre pueda necesitar de la ciencia. Basta haberlo experimentado una vez para comprenderlo. Wittgensteins comprendió muy bien que la ciencia no roza la vida. Russell afirmaba que las preguntas de la filosofía no encuentran la solución en los laboratorios. Y Ortega nos advierte sabiamente que «porque la ciencia experimental sea incapaz de resolver a su manera esas cuestiones fundamentales no es cosa de que, haciendo ante ellas un gracioso gesto de zorra hacia uvas altaneras, las llame 'mitos' y nos invite a abandonarlas... Y no es pretexto bastante para esa insensibilidad hacia las últimas cuestiones declarar que no se ha hallado manera de resolverlas. ¡Razón de más para sentir en la raíz de nuestro ser su presión y su herida! ¿A quién le ha quitado nunca el hambre saber que no podrá comer? (...). La 'verdad científica' es una verdad exacta, pero incompleta y penúltima, que se integra forzosamente en otra especie de verdad, última y completa, aunque inexacta, a la cual no habría inconveniente en llamar 'mito'. La 'verdad científica' flota, pues, en mitología, y la ciencia misma, co- 
mo totalidad, es un mito, el admirable mito europeo" ${ }^{37}$. La filosofía no es estéril porque no haya conseguido arrancar la verdad a las cosas y decir la última palabra universalmente aceptada. Ha logrado, sin embargo, gratificar al hombre, enfrentándolo con el misterio que todo lo penetra y envuelve, infundiéndole respeto por lo real y haciendo que se sienta a gusto en su mundo. La filosofía, dice Hegel, es precisamente esto mismo, pues, «no consiste sino en que el hombre viva a gusto en su espíritu, se sienta en él como en la intimidad $"{ }^{38}$. Las épocas sin filosofía no consiguen hacer habitable su propia morada. Todo es inhóspito. El escepticismo ingenuo, que no sabe nada porque se lo sabe todo, no tiene cabida cuando la filosofía se la enseña desde su dimensión humana que es donde comienza inevitablemente y donde perdura necesariamente. La filosofía, puntualiza Gusdorf, no comienza en Tales de Mileto, «no comienza en ninguna parte de la historia como las matemáticas o la biología, no comienza en un punto en el que una investigación suficientemente informada pudiera asignar. La filosofía se impone como una tarea y el carácter propio de la filosofía es que esta tarea no la puede realizar ninguna persona intermediaria» ${ }^{39}$. En filosofía no es posible encontrar un suplente ${ }^{40}$.

El carácter irrevocablemente personal de la filosofía que imposibilita para aceptar pasivamente las respuestas del otro puede llevar a excluir las preguntas de los demás. Caer, sin embargo, en el dogmatismo es tan poco filosófico como el excepticismo, cuando uno excluye toda duda y el otro toda certeza. No se puede olvidar que Platón corrigió constantemente sus ideas y cuando le sorprende la muerte su filosofía está aún por hacer. Kant se afana infructuosamente por edificar un sistema cuando le fallan las fuerzas ${ }^{41}$. Aristóteles fue el mejor discípulo de Platón como Marx lo fue de Hegel ${ }^{42}$. Las preguntas, decía Jaspers, son más importantes que las respuestas. La filosofía hecha y acabada, la que no deja margen para las preguntas, carece de sentido histórico y de valor pedagógico. Althusser reprocha a la filosofía el que en ella no tenga cabida el error, el que sólo se equivoque para los demás y nunca para sí misma. Descartes, por el contrario, pensaba de otra manera, no obstante todas sus evidencias e ideas claras, cuando reconocía lo 'privado' del método, la posibilidad de que entrañara error. Sólo le animaba el pensar que algunos en-

37. ORTEga y Gasset, J., ¿Qué es filosofía? El Arquero. Ed. Revista de Occidente. Madrid 1971, pp. 68-69. p. 141.

38. Hegel, G.W.F., Lecciones sobre la historia de la filosofía. Ed. F.C.E., México 1977,

39. GuSDORF, G., Traité de métaphysique. Ed. Armand Colin, 1956, p. 17.

40. Id., p. 19.

41.' Véase sobre este punto Ortega y Gasset, J., Kant, Hegel, Dilthey. Ed. Revista de Occidente. El Arquero, Madrid 1973, p. 58.

42. GuSDORF, G., ¿Para qué los profesores? Ed. Cuadernos para el diálogo. Madrid 1973, pp. $146,173,178$. 
contraran algo que pudieran seguir y, sobre todo, su sinceridad, su ánimo verdadero ${ }^{43}$.

La filosofía no puede contentarse nunca con lo establecido. Nadie mejor que ella sabe que con un número limitado de elementos puede obtener un número indefinido de formas. La filosofía es eminentemente crítica. No se trata de criticar por criticar, sino de impedir con ello que el hombre tome por absoluto lo que no es más que episódico. Nos dice sugestivamente André Gide «que la mujer de Loth, por haber querido mirar hacia atrás, fue convertida en estatua de sal, es decir: de lágrimas cuajadas» ${ }^{44}$. Se critica lo que ya no tiene vida ni vigencia. La crítica que emprende la filosofía, observa Max Horkheimer, no es «la condena de una cosa cualquiera, ni el maldecir contra esta o aquella medida; tampoco la simple negación o rechazo (...); es el esfuerzo intelectual... por no aceptar sin reflexión y por simple hábito las ideas; es impedir que los hombres se abandonen a aquellas ideas y formas de conducta que la sociedad en su organización actual les dicta; es el esfuerzo por armonizar, entre sí y con las ideas y metas de la época, los sectores aislados de la vida social; es luchar para que no desaparezca de la tierra la fe en un futuro digno del hombre» ${ }^{45}$. El filósofo tiene que mantener vivo el misterio de lo real que se oculta si quiere impedir los absolutismos que deshumanizan. Esto no es tarea fácil y menos hoy en que el ciudadano ya no está seguro, como observa Merleau-Ponty, de que el mundo humano sea posible ${ }^{46}$.

Si la filosofía quiere devolver la esperanza al hombre y la razón a la sociedad, sólo puede echar raíces en su verdadero fundamento que es el hombre.

\section{La enseñanza del saber filosófico no es ya la entrada en filosofía}

El carácter individual de la experiencia filosófica, esa experiencia que es siempre la mía en su aspecto más personal, exige del profesor dedicar todo su esfuerzo y atención porque la filosofía no tiene un comienzo. En filosofía no existe en rigor una 'introducción' porque en ella la primera palabra es ya la última. Decimos que la filosofía comienza con la admiración, lo que vale tanto como decir que comienza con una palabra inarticulada, desconceptualizada. Sabemos lo que nos admira y cómo, pero se nos oculta lo más importante, su porqué. El filósofo, el maestro del pensamiento, necesita toda su vida, sin la garantía de conserguirlo como son los casos de Platón, Kant o Heidegger, para articular la palabra originaria, lo vivido con radicalidad y ultimidad. Decía Hegel que en filosofía todo inicio es sólo relativamente inicio ya que aquello

43. Descartes, R., Discurso del método. Ed. Espasa-Calpe. Madrid 1975, p. 30.

44. Gide, A., Los alimentos terrestres y los nuevos alimentos. Ed. Losada, Buenos Aires 1953 , p. 154.

45. Horkheimer, M., Teoría crítica. Ed. Amorrortu, Buenos Aires 1974, pp. 288, 282, 289.

46. Merleau-Ponty, M., Sentido y sinsentido. Ed. Península, Barcelona 1977, p. 29. 
por lo que se comienza es lo que ha de aparecer más tarde como resultado. La filosofía es una curva que se cierra sobre sí misma, forma un círculo ${ }^{47}$. No hay propiamente hablando una introducción, sino un instalarse ya dentro del ámbito filosófico. Heidegger nos habla frecuentemente de una entrada 'de golpe', súbita que, además, no se puede repetir a capricho. Platón describe el acceso a la ciencia absoluta como un 'salto' desde los trampolines que son las hipótesis. Lo mismo hace san Agustín cuando quiere llevarnos a contemplar el bien supremo. Se detiene inesperadamente para decirte: ahora, contémplalo si puedes. El método falla siempre en el momento más inoportuno, en el momento de la intro-ducción. El profesor de filosofía debe ser consciente de esto para que el alumno que accede por vez primera a la filosofía no confunda el cúmulo de conocimientos filosóficos con la filosofía. En este sentido las primeras lecciones tienen una importancia excepcional, y las lecturas de textos autobiográficos pueden prestar extraordinaria ayuda.

Cuando la filosofía se resuelve solamente en introducción a los saberes filosóficos, aquélla se convierte en 'historia de la filosofía', es decir, en panteón de ilustres pensadores y sus profesores dan la impresión de ser 'los guardianes de la necrópolis' y los especialistas de la momificación. La enseñanza de la filosofía es más que historia. Lo principal en la enseñanza de la filosofía no es su historia. Esto no significa, en modo alguno, eliminar la historia en la enseñanza de la filosofía. Son muchos los pensadores que han sacrificado su vida tratando de responder a los interrogantes postreros y dramáticos que torturan al hombre ¿qué sentido tiene la vida? ¿de dónde viene y a dónde va el mundo? $\mathrm{El}$ profesor de filosofía no puede abandonarse a improvisaciones temerarias, no puede ignorar las soluciones más relevantes recogidas por la historia. La reflexión sobre el misterio del cosmos, del hombre, de la vida es tan antigua como el mundo. También el mito, dice Ortega, es teoría que busca 'fundamentar' una conducta o acción ${ }^{48}$. La mitología responde a esa grave urgencia que tiene el hombre de entrar en paz consigo mismo y con su mundo. «El mito, afirma Gusdorf, es la primera forma de adaptación espiritual de la comunidad humana en su contorno. Procura él una primera lectura del mundo, una primera ubicación en el espacio y en el tiempo" ${ }^{49}$. Previa a las complicadas y abstrusas fabulaciones está la vida intensa del espíritu. La filosofía comienza con la vida del hombre. No se puede olvidar a los que nos han precedido. El recurso a la historia como medio llevado no con afán de mera erudición, sino como apoyo de la enseñanza teórica no está, en modo alguno, en contradicción con lo que hemos indicado anteriormente referente a la filosofía como una tarea que hay que comenzar a cero y como si nada hubiera sido hecho has25.

47. Citado por G. Gusdorf en Traité de métaphysique. Armand Colin, Paris i 1956, pp. 24-

48. Puede verse Ortega y Gasset, J., Kant, Hegel, Dilthey. Ed. Revista de Occidente. El Arquero, Madrid 1973, p. 216.

49. Gusporf, G., Mito y metafísica. Ed. Nova, Buenos Aires 1960, pp. 267-268. 
ta el presente. El hombre, en realidad, no puede comenzar a cero porque tiene mucho de producto histórico. Entre nosotros y la realidad a examinar está la historia. El hombre nace en una situación contextual que actúa a manera de fondo previo de significatividad y que nos instala en lo real. Descartes, Kant, Husserl, etc., sólo pueden hacer tabla rasa del pasado como presente. «Nuestra manera de insertarnos, sostiene Gusdorf, no depende solamente de nuestra 'encarnación biológica', que como un ámbito vital nos baña y nos une a la naturaleza, sino también por la 'encarnación social' que comprende el ámbito humano de los valores, comportamientos, pensamientos que nos bañan vitalmente. La existencia humana está transida de cultura, de civilización, de historicidad que la nutre mentalmente, semánticamente, e impone al pensamiento y a la conciencia una dirección y un modo peculiar de 'ver' el universo. Se hace filosofía desde una situación cultural ${ }^{50}$. No se puede, pues, prescindir de la historia. A través de ella el alumno debe aprender también que el pensamiento surge en colaboración, en unión con el pasado que ha hecho posible el presente. Comenzar a cero sólo puede significar comenzar desde otro punto de vista, pero no desde fuera de la historia.

\section{Lo inactual de la filosofía}

La filosofía surge en un momento determinado, «en un aquí y en un ahora fijos, incanjeables». Ortega ha visto bien que el ambiente es uno de los ingredientes de nuestra personalidad, que «cada uno de nosotros es por mitad lo que él es y lo que es el ambiente en que vive» ${ }^{51}$, que «la vida es, a la vez, fatalidad y libertad, es ser libre dentro de una fatalidad dada» ${ }^{52}$. No podemos, pues, olvidar, descuidar o minimizar esta realidad. La filosofía es siempre actual, contemporánea del momento en que se vive, de lo contrario sería una filosofía abstracta para no se sabe quién. En realidad no sería filosofía. Pero también esto requiere sus matices. $\mathrm{Ni}$ el maestro ni el alumno deben quedar fascinados por la 'modernidad' de la filosofía. Un filósofo como Heidegger, cuya obra "Ser y tiempo" constituye el mejor manual del existencialismo, ha expresado claramente el carácter inactual de la filosofía. Dice así: «La filosofía es esencialmente inactual, pues pertenece a esas pocas cosas destinadas a no poder encontrar eco en el hoy actual y que, además, no debe encontrarlo. Por eso, cuando todo parece suceder al contrario, cuando una filosofía llega a ser una moda, entonces, o no se trata de verdadera filosofía o ha sido tergiver-

50. Puede consultarse Gusdorf, G., Traité de métaphysique. Armand Colin, Paris 1956, p. 356.

51. Ortega y Gasset, J., ¿Qué es filosofia? Ed. Revista de Occidente. El Arquero, Madrid 1971 , p. 50.

52. Id., p. 252. 
sada o interpretada abusivamente por exigencias del día, que corresponden a intenciones que le son completamente ajenas» 5.3.

La filosofía es, efectivamente, inactual porque su problema es siempre el mismo: el hombre en busca de su orientación definitiva y de una existencia plena. Heidegger abre su obra con una cita tomada de «El sofista», de Platón. En aquel diálogo dice el extranjero: «... A vosotros os corresponde hacernos ver con toda claridad qué es lo que queréis significar con esta palabra 'ser'. Pues, sin duda, desde hace mucho tiempo estáis familiarizados con lo que queréis decir cuando usáis la palabra 'ser'. En cuanto a nosotros, creíamos hasta el momento comprenderla, mas ahora nos encontramos perplejos»" ${ }^{54}$. Heidegger reemprende con estas palabras la búsqueda del eterno e inactual objeto de la filosofía: el ser. El texto le ha dado motivo para replantear la pregunta. « $¿$ Tenemos hoy una respuesta a la pregunta que interroga por lo que queremos decir propiamente con la palabra 'ser'? En manera alguna. Por eso conviene poner de nuevo la cuestión del sentido del ser» ${ }^{55}$.

Hasta aquí hay que dar la razón a Heidegger, la filosofía es inactual. Pero cuando Heidegger nos propone el modo de llevar a cabo la pregunta por el ser, la filosofía se hace actual. Más aún, no puede menos de ser actual. En primer lugar, observa Heidegger, hoy no sentimos la menor incomodidad ni perplejidad porque no comprendemos la palabra 'ser'. Esto hace que debamos' comenzar, ante todo, a despertar la comprensión y audiencia para el sentido de esta pregunta. Y para despertar esa comprensión y audiencia, la pregunta hay que plantearla desde algo tan concreto como el mundo interior del hombre: «la elaboración concreta de la cuestión del sentido del ser es el objeto del presente tratado. Su meta provisional es proporcionar una interpretación del tiempo como horizonte de toda comprensión posible del ser» ${ }^{56}$.

Sabemos que la 'elaboración concreta' de las cuestiones fue la pauta y el criterio dominante en la llamada corriente existencialista. La ontología o la metafísica sólo era válida si se edificaba sobre un análisis minucioso, atento a toda pulsión intravital o intraespiritual del ser concreto y singularísimo que es el hombre. Al ser en general sólo se puede llegar a través de una teoría del ser del hombre concreto. El método no podía ser otro que fenomenológico. Así presentaba Heidegger el planteamiento actual de una cuestión inactual. La filosofía es de suyo inactual, pero los modos de acceso a su cometido son actuales y no pueden ser de otro modo si quiere que esos graves problemas del hombre tengan audiencia, que, en definitiva, no es otra cosa que intentar que

53. Heidegger, M., Einführung in die Metaphysik. Ed. Max Niemeyer, Tübingen 1958, p. 6 .

54. Platón, El sofista, 244b.

55. Heidegger, M., Sein und Zeit. Ed. Max Niemeyer, Tübingen 1957, p. 1 .

56. Id., p. 1 . 
el hombre no decaiga, sino que en todo momento pueda recuperar su dimensión más específicamente humana.

El carácter 'actual' de la filosofía no es algo meramente arbitrario, pertenece a esa necesidad o fatalidad que se llama 'momento histórico', 'contexto cultural', etc., que constituye el fondo de sensibilidad y significatividad a partir del cual pueden plantearse problemas y cuestiones que tengan sentido. El profesor de filosofía no puede olvidarlo si quiere ahorrar esfuerzos. La enseñanza de la filosofía debe partir teniendo en cuenta esos modos dominantes de sentir que nos vienen dados por el mero hecho de estar insertos en un ambiente que conlleva un modo secreto de filosofía.

\section{Comunicar lo incomunicable}

Nos transmite Aristóteles las palabras con las que Heráclito saludó a aquellos extranjeros que habían emprendido viaje para visitarle. Esperaban encontrar en el filósofo un ser extraño, raro, enigmático, un mago o un místico hablando en lenguajes arcanos y misteriosos. Nada de esto sucedió. Lo que presenciaron al entrar fue una de las escenas más banales de la vida diaria. Se encontraron con un hombre que tenía frío y se calentaba junto a un horno de pan. No valía la pena una peregrinación para encontrar aquello. Pero $\mathrm{He}$ ráclito les saca de su primera desilusión transformando aquella escena vulgar y cotidiana con este simple saludo: "entrad sin dudarlo, también aquí hay dioses». Los dioses también están aquí abajo, junto a las necesidades más humildes y más humanas, junto al calor y el pan. El filósofo también está allí junto a las cosas más elementales, junto a lo más simple y anodino de la vida para hacer brotar algo divino. El filósofo no se aparta de lo real, al contrario, lo vive y con su vida lo potencia y desvela la fuerza vivificadora de lo sencillo. «Los dioses también están aquí»; el hombre vive en pleno misterio y esto no debe dejarle tranquilo.

La filosofía, como la vida misma, se comunica y se contagia. San Agustín escribía para todos los públicos y en sus homilías enseñaba filosofía a un pueblo rudo e inculto que poco a poco aprendía a mirar la realidad con otros ojos. Mónica, su madre, que no había recibido formación intelectual alguna, participaba en los diálogos filosóficos y llegó, según dice san Agustín, a conquistar la fortaleza de la filosofía. Platón, Aristóteles, santo Tomás de Aquino, Kant, Hegel dedicaron su vida a la enseñanza de la filosofía. Toda filosofía, por lo demás, se constituye en doctrina, es decir, en algo que pueda ser enseñado. Pero tampoco podemos exagerar este aspecto de la comunicabilidad. Cuando san Agustín quiere comunicarnos, en sus «Confesiones», su experiencia de Dios llena su discurso de términos contrapuestos para terminar diciendo que no es nada de todo aquello que ha dicho. Heidegger interrumpe 
la línea de investigación del «Ser y tiempo» porque el lenguaje filosófico era incapaz de expresar su experiencia. Luchó toda su vida por aclarar su 'evidencia' y no lo logró. Los pensadores y los poetas se lamentan de la pobreza del lenguaje. Están convencidos que más que 'decir' lo que hacen es 'evocar', 'insinuar', 'manifestar'. «La poesía en rigor, dice Ortega, no es lenguaje. Usa de éste, como mero material, para trascenderlo y se propone expresar lo que el lenguaje sensu stricto no puede decir. Empieza la poesía donde la eficacia del habla termina. Surge, pues, como una nueva potencia de la palabra irreductible a lo que ésta propiamente es». Solamente así «todo decir es exuberante no por lo que 'dice', sino por lo que 'manifiesta' ${ }^{57}$. El 'último' Heidegger también optó por el camino de la poesía.

Cuando se afirma que la filosofía es comunicar lo incomunicable no se pretende significar que la enseñanza de la filosofía esté abocada al fracaso insuperable por más esfuerzos que se empleen en evitarlo. La filosofía es comunicable aunque su objeto, en su último reducto, no lo sea. El pensador escribe sus obras no solamente para aclararse a sí mismo, para decirse a sí mismo lo que ha visto, sino para decírselo a los demás, para someterlo a la consideración y juicio de los otros. A veces es el profesor quien dificulta la comunicación y contribuye con su léxico a que los alumnos se formen ideas erróneas sobre la filosofía. Un lenguaje excesivamente técnico, rebuscado y exótico ocultan verdades de las más evidentes.

Sin embargo, el rigor técnico hay que mantenerlo. Es preciso evitar el extremo fácil de la simplificación. La enseñanza de la filosofía no debe descender, guiados por un afán didáctico de claridad y accesibilidad, a detalles concretos. Cuando se desciende al terreno de la vulgarización, la filosofía se desvirtúa. Si afirmamos, por ejemplo, que, según el pensamiento sartriano, elegimos constantemente en la angustia, esto no se puede aclarar ni contradecir recurriendo al ejemplo de si la elección entre un hojaldre y un pastelillo de crema de chocolate sea una elección hecha en la angustia, ya que la angustia es constante en el sentido de que mi elección original es una cosa constante ${ }^{58}$. El profesor de filosofía debe permanecer a la altura del ámbito en el que se mueve. No se puede olvidar que el esfuerzo lo tienen que realizar también los alumños y no menor que el profesor. Los prisioneros en el mito de la caverna que nos refiere Platón tienen que volverse física y mentalmente para poder ver la realidad auténtica. La filosofía exige un alto precio. La lectura directa de los pensadores, bien llevada, hace más comprensibles las enseñanzas del profesor, además de contribuir poderosamente a despertar la ilusión por la

57. Ortega y Gasset, J., Velázquez. Ed. Espasa-Calpe. Col. Austral, Madrid 1970, p. 49. p. 101 .

58. SARTre, J.-P., L'existentialisme est un humanisme. Ed. Nagel, Paris 1960, p. 1960, 
filosofía y a sentir respecto por lo incomunicable. La lectura de los buenos libros, decía Descartes, es una conversación con los mejores ingenios ${ }^{59}$.

\section{8. ¿Lectura de textos o lectura de libros?}

Los manuales, inevitablemente por su carácter de resumen, nos presentan la filosofía ajena al calor humano de su gestación inicial. No se puede negar, por supuesto, la gran ayuda que proporcionan por más que Ortega les califique de 'remediavagos' ${ }^{60}$ y Châtelet les trate de 'chapuzas intelectuales' ${ }^{61}$. Los manuales son siempre una guía, un programa más desarrollado. Pero, evidentemente, nunca podrán sustituir la filosofía en su proceso de elaboración. El profesor necesita completarlos a fondo. El profesor que no reanima los manuales de filosofía, que olvida que la novela 'La náusea' precede a 'El ser y la nada', como la vida al pensamiento, se expone a provocar en los alumnos el más anodino indiferentismo. Se puede completar los manuales con la lectura de obras, no de textos. Un texto del 'Discurso del método' no logrará nunca dar una idea ni de la obra ni del autor. El texto es siempre fragmentario, arrancado del contexto, separado de la vida de apasionada búsqueda del autor. A su vez, se ve privado de esa extraordinaria calidad que tienen los grandes pensadores de inspirar, sin pretenderlo, otras ideas. Leer una obra no es fácil para el alumno y tampoco lo es para el profesor, que no solamente ha debido leérsela previamente, sino que debe preparar el guión para facilitar la lectura al alumno. No basta una introducción al pensamiento del autor y a la obra. Deberá presentar al alumno una serie de preguntas breves, concisas, que puedan figurar como puntos o apartados de un tema y que el alumno deberá confirmar con textos, todos los posibles, sacados de la obra en cuestión. Deberá consignar también el alumno las páginas de los textos paralelos. Con aquella base de apartados, puntos y 'pistas' se consigue evitar la pérdida inútil de tiempo. A veces se encarga al alumno un trabajo - el que quiera, se le dice - sobre una obra; es muy frecuente en estos casos que el alumno, leída la obra, no haya encontrado aún ni un solo tema que pudiera desarrollar. Se trata, pues, de que el alumno comience la lectura sabiendo lo que va a buscar. Con este método no solamente se le enseña, en la práctica, a hacer trabajos, a seleccionar textos, sino que aprende a sintetizar ya que los puntos e interrogantes que le facilita el profesor expresan el eje que une una serie de pensamientos de la obra. Como compensación el alumno se sentirá creador y conservará su trabajo durante miucho tiempo. Cada alumno deberá leerse una

59. Descartes, R., Discurso del método. Ed. Espasa-Calpe. Col. Austral, Madrid 1975, 1975, p. 31.

60. Ortega y Gasset, J., ¿Qué es filosofía? Ed. Revista de Occidente. El Arquero, Madrid 1971 , p. 195.

61. ChÂtelet, F., La filosofía de los profesores. Ed. Fundamentos, Madrid 1971, p. 111. 
obra, no todos la misma y, a ser posible, cada una de ellas corresponderá a un tema del programa. De este modo, los mismos alumnos habrán confeccionado su propio texto. La exposición sintética que cada alumno hará de su tema en clase, además de servir como ejercicio de expresión, puede utilizarse como método de repaso, discusión, etc. Siempre será, por otro lado, una buena ocasión para conocer las obras también en su aspecto exterior.

\section{Consideración final}

El clima filosófico de nuestros días se ha embarcado en un fascinante suicidio intelectual dispuesto a acabar, contradictoriamente, con la enseñanza de la filosofía y la filosofía misma. Al hombre le gusta jugar, de vez en cuando, a ese juego peligroso de no hacer, como los dioses, filosofía. No necesitamos ir muy lejos para comprobar que no es un mal exclusivo de nuestra época. Hegel, en el discurso con el cual inauguraba su Curso de Historia de la filosofía, confesaba lo mismo de la suya, si bien comenzada ya, en cierto modo, a mostrarse optimista. Decía así: «Parece haber llegado la hora de que la filosofía pueda confiar en encontrar de nuevo la atención y el amor a que es acreedora, en que esta ciencia, que había llegado casi a enmudecer, recobre su voz y sienta revivir la confianza de que el mundo, que parecía haberse vuelto sordo para ella, la escuche de nuevo. La miseria de la época daba una importancia tan grande a los pequeños y mezquinos intereses de la vida cotidiana, los elevados intereses de la realidad y las luchas sostenidas en torno a ellos embargaban de tal modo toda la capacidad y todo el vigor del espíritu, absorbían a tal punto los recursos materiales, que las cabezas de los hombres no disfrutaban de la libertad necesaria para consagrarse a la vida interior, más alta, y a la pura espiritualidad, lo que hacía que las mejores capacidades se vieran absorbidas por aquellas preocupaciones y, en parte, sacrificadas a ellas» ${ }^{62}$.

Nuestra época, por supuesto, no es aquélla. Vivimos en la época técnicoindustrial: desasosiego, insatisfacción angustiosa y temor de aniquilamiento total, degradación de las condiciones de vida y de las relaciones humanas, diferencias inhumanas entre los pueblos y entre los hombres, etc. Estas lagunas y deficiencias substanciales traen, afortunadamente y cada vez con mayor claridad, la conciencia de que una civilización montada sobre la eficacia de la técnica no se ha conseguido, en el fondo, aliviar la existencia del hombre. «Pese al avance de la ciencia y la técnica, dice Horkheimer, es notorio que los hombres empobrecen material, emocional y espiritualmente» ${ }^{63}$. El recurso, como un gesto último desesperado de salvación, a sabidurías anteriores al na-

62. Hegel, G.W.F., Lecciones sobre la historia de la filosofía. Ed. F.C.E., México 1977, p. 3.

63. Horkheimer, M., Teoría crítica. Ed. Amorrortu, Buenos Aires 1974, p 278. 
cimiento de la filosofía deja al descubierto la tarea inmensa que le queda por hacer a la filosofía, su necesidad y su 'utilidad'. Es cierto que para la técnica la filosofía es inútil, superflua, está de más. También dijo Aristóteles que la filosofía es inútil porque "sólo después de haber cubierto las necesidades elementales de la vida, se ha empezado a filosofar" ${ }^{64}$. La filosofía no entra dentro de la utilidad que remedie las exigencias y necesidades materiales para mantenerse en la vida. Hay que decir con Hegel que «la filosofía es un lujo» ${ }^{65}$. Pero hay que hablar también con Aristóteles y con Hegel de la potencia de lo inútil. Heidegger habla continuamente de este poder en cuanto que la filosofía constituye una gratificación y promoción ontológica del hombre que le proporciona una morada y un hogar en la tierra. La filosofía hace que el hombre se sienta a gusto en su mundo. El exilio, nos dice Heidegger, que padece el hombre de nuestros días no es porque se encuentre fuera de su casa, sino porque no ha conseguido hacerla habitable. Por eso, desde su punto de vista de la vida del hombre, de su pensamiento, de su corazón y de su espíritu la filosofía es tan necesaria como inevitable. La filosofía tiene la fecha del hombre. Concierne a la filosofía la inestimable tarea de humanizar el mundo.

La filosofía, nos dice Hegel, se gesta en algo tan humano como es la decadencia, la derrota, la crisis. El pájaro de Minerva no levanta su vuelo hasta la caída del crepúsculo. La filosofía surge cuando una forma de pensamiento y de vida cede, cruje, llega a su ocaso, cuando se abre una ruptura entre el mundo interior y exterior. De aquí nuestra insistencia en la necesidad de presentar la filosofía al alumno como vida del espíritu. De ahí también la conveniencia de exponer genéticamente el pensamiento de los grandes filósofos; y de ahí, a su vez, la necesidad de dar primacía a la lectura de obras sobre los textos. Mientras se transmite el saber filosófico es preciso comunicar el espíritu de la filosofia que se afana por ver las cosas por dentro. Lo más importante de los sistemas filosóficos no son los resultados ni las conclusiones porque no nos comunican algo fijo, estable e innegable sobre la realidad. Las doctrinas filosóficas se niegan y se refutan indefinidamente y estamos seguros que no aparecerá una filosofía que sea capaz de poner fin a la filosofía a pesar de que toda filosofía está impulsada por un secreto e inconfesado instinto de muerte ${ }^{66}$. Todo sistema sucumbe muy a pesar suyo. Por ello, lo más valioso de los sistemas filosóficos es el mundo que nos descubren, la transformación que operan sobre lo real de modo que las cosas aparecen como si fuera la primera vez que las vemos. Descubriendo lo real nos libera de lo rutinario. La filosofía es fundamentalmente promoción humana. No se trata de interpretar estéticamente la filosofía o de reducirla, en sus resultados, a un inofensivo placer estético. El

64. ARISTóteles, Metafísica, I, 2.

65. HeGEL, G.W.F., o.c., p. 53.

66. Puede verse sobre este aspecto G. Gusdorf, Traité de métaphysique. Ed. Armand Colin, Paris 1956, p. 42. 
hombre no puede contemplar desapasionadamente lo real porque su ser está en juego en plena tempestad del misterio. Los filósofos ofrecen modelos de reflexión. Por ello, en filosofía 'aprender' sólo puede tener sentido cuando significa aprender a reflexionar. Todo lo demás es erudición inútil. No se puede olvidar lo que nos decía Jaspers a propósito de la etimología de la palabra 'filosofía'. La filosofía no es la posesión de la verdad, sino el amor, el deseo y la búsqueda de la verdad. No es su propietario, sino su peregrino.

José Luis CANCELO

Colegio Mayor San Agustín

Ciudad Universitaria

Madrid 